\title{
Mid-trimester diagnosis of bladder neck obstruction by ultrasound and paracentesis
}

\author{
JOSEF SHALEV, ZION BEN-RAFAEL, BOLESLAV GOLDMAN*, \\ I ENGELBERG $\dagger$, AND SHLOMO MASHIACH
}

Department of Obstetrics and Gynecology, *Institute of Human Genetics, and †Department of Pathology, Chaim Sheba Medical Center, Sackler School of Medicine, Tel-Aviv University, Tel-Hashomer, Israel.

SUMMARY A bladder neck obstruction was suspected after ultrasound investigation at 16 weeks' gestation. Evaluation of protein content in the amniotic fluid, fetal ascites, and fluid from the overdistended bladder supported the diagnosis. Bladder outflow obstruction in the second trimester of pregnancy was not associated with raised alphafetoprotein levels in the amniotic fluid and maternal serum.

Ultrasonic diagnosis of fetal urinary tract malformations and in utero treatment of urinary tract obstruction has been previously reported. ${ }^{1-3}$ The identification of an intra-abdominal cystic structure such as the fetal bladder may be difficult, as retention of up to $3500 \mathrm{ml}$ urine has been reported. ${ }^{4}$ In this report ultrasonic guided paracentesis and chemical analysis of the fetal and amniotic fluids were performed for antenatal diagnosis which enabled early termination of the pregnancy.

\section{Case report}

A 28-year-old woman, Gl, PO, underwent routine ultrasonic examination at 16 weeks' gestation. A single fetus was observed with a BPD of $29 \mathrm{~mm}$, appropriate for gestational age. The fetal abdomen was distended by a $11 \mathrm{~cm} \times 7 \mathrm{~cm}$ cystic mass (fig 1 ) and the viscera were totally compressed against the chest. A lethal anomaly was suspected. After gaining the parents' informed consent, the pregnancy was terminated by intra-amniotic infusion of hypertonic saline. During this procedure amniotic fluid was tapped and the contents of the cystic structure partially aspirated. Thereafter, free intra-abdominal fluid (ascites) in the fetus was successfully aspirated.

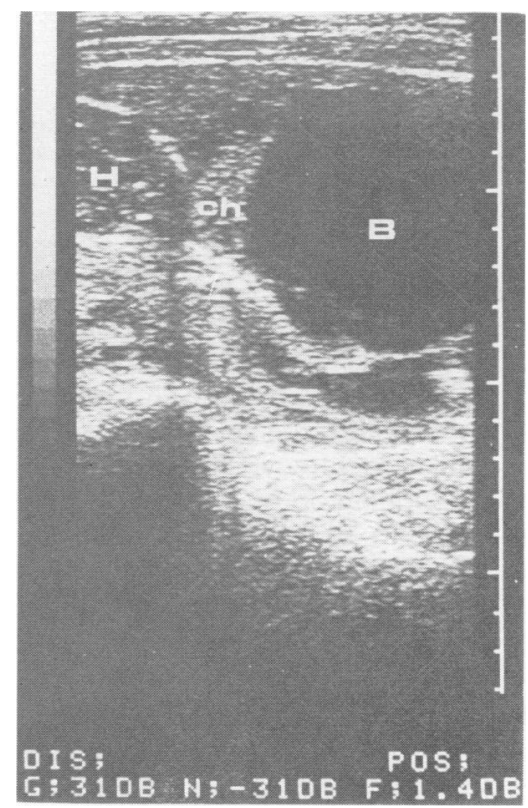

FIG 1 Real-time echograph $9 \mathrm{~cm}$ above the symphysis pubis demonstrating the grossly dilated fetal bladder $(B)$. Fetal viscera are compressed against the fetal chest (ch) and the fetal abdomen is much larger than the fetal head $(H)$.

TABLE Chemical analysis of fetal and amniotic fluid samples obtained by paracentesis.

\begin{tabular}{lccc}
\hline Laboratory data & Amniotic fluid & Ascites & Cystic structure \\
\hline Sodium (mEq/l) & 137 & 83 & 98 \\
Potassium (mEq/1) & $3 \cdot 7$ & $2 \cdot 6$ & $2 \cdot 9$ \\
Chloride (mEq/l) & 108 & 75 & 84 \\
Glucose (mg/dl) & 34 & 64 & 44 \\
Total protein & 800 & 175 & 10 \\
$\quad$ & & & \\
\hline
\end{tabular}




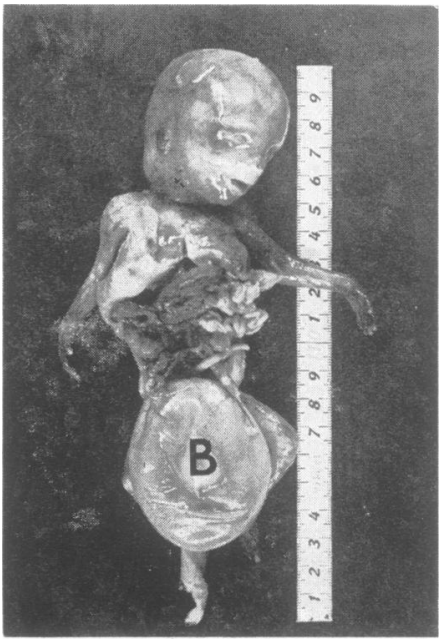

FIG 2 Anatomical preparation of the fetal urinary tract with a huge bladder $(B)$.

The chemical analysis of the fluid samples obtained (amniotic fluid, fluid from the cystic structure, and fetal ascites) are given in the table. A clear difference in protein content was observed in the three fluids, with the lowest values being in the fluid aspirated from the cystic structure which represented the fetal bladder. The alphafetoprotein level in the amniotic fluid was found to be normal. Eighteen hours after amniocentesis a male fetus was aborted. Necropsy confirmed the presence of bladder neck obstruction (fig 2).

\section{Discussion}

The successful diagnosis of urinary tract malformation in an uneventful pregnancy stresses the importance of routine ultrasonic screening in the second trimester.

Differential diagnosis of a fetal intra-abdominal cystic mass may be difficult. Evaluation of its fluid content might help in reaching the diagnosis. The presence of bile acid in the amniotic fluid positively supported the diagnosis of intestinal obstruction. ${ }^{5}$ Nevin $e t a^{6}$ found raised alphafetoprotein levels in the amniotic fluid in cases of overdistended fetal bladder caused by absence of the urethra. Chemke et $a l^{7}$ reported Meckel's syndrome associated with polycystic kidneys in which raised alphafetoprotein was found. Kjessler $e t a l^{8}$ observed raised alphafetoprotein in congenital nephrosis. In our case the AFP level in the amniotic fluid was found to be normal. This was probably owing to secondary intestinal obstruction proximal to the duodenum, caused by the extremely overdistended bladder, which partially prevented regurgitation of bile into the amniotic fluid.

The decision as to whether to treat low urinary tract obstruction in utero or to terminate the pregnancy is based upon the degree of renal damage and the ability to recuperate. Dynamic ultrasound studies of renal function in cases of bladder neck obstruction or posterior urethı al valve are of limited value, because they are based on the normal functioning of the urinary bladder. ${ }^{9}$ Abnormal alphafetoprotein levels in the amniotic fluid do not indicate the presence of urinary tract malformations. Fuither studies of the composition of the urine at various stages of pregnancy and ultrasonic evaluation of renal anatomy could be important future methods in determining the degree of renal damage in cases of bladder outflow obstruction.

\section{References}

1 Shalev J, Itzchak Y, Blau H, et al. The prenatal diagnosis of urethral obstruction and diverticulum of the urinary bladder. Pediatr Radiol 1982;12:48-5J.

2 Harrison MR, Filly RA, Oarer JT, Faer MJ, Jacobson JB, De Lorimier AA. Management of the fetus with a urinary tract malformation. JAMA $1981 ; 246$ :635-9.

3 Golbus MS, Harrison MR, Filly RA, Callen PW, Katz M. In utero treatment of urinary tract obstruction. $\mathrm{Am}$ J Obstet Gynecol 1982;142:383-8.

4 Garrett WJ, Kossof G, Osborn RA. The diagnosis of fetal hydronephrosis, megaureter and urethral obstruction by ultrasonic echography. Br J Obstet Gynaecol 1975;82: 115-20.

5 Deleze G, Sidiropoulos D, Paumgartner G. Determination of bile acid concentration in human amniotic fluid for prenatal diagnosis of intestinal obstruction. Pediatrics 1977;59:647-50.

${ }^{6}$ Nevin NC, Ritchie A, McKeown F, Roberts G. Raised alpha-fetoprotein levels in amniotic fluid and maternal serum associated with distension of the fetal bladder caused by absence of urethra. J Med Genet 1978;15:61-3.

7 Chemke J, Miskin A, Rav-Acha Z, Porath A, Sagiv M, Katz Z. Prenatal diagnosis of Meckel syndrome: alphafetoprotein and beta-trace protein in amniotic fluid. Clin Genet 1977;11:285-9.

8 Kjessler B, Johansson SGO, Sherman M, Gustavson KH, Hultquist G. Alphafetoprotein in antenatal diagnosis of congenital nephrosis. Lancet 1975 ;i:432-3.

- Wladimiroff JW, Campbell S. Fetal urine production rates in normal and complicated pregnancy. Lancet $1974 ; \mathbf{i}: 151-4$.

Correspondence and requests for reprints to Dr Josef Shalev, Department of Obstetrics and Gynecology, Chaim Sheba Medical Center, Tel-Hashomer, Israel. 